\title{
Creative Activism: a pedagogical and research tool
}

Ruth Morrow, University of Ulster 


\section{Abstract}

Environmental activism has a long history in protest, addressing issues of degradation and segregation that threaten existing ecologies, social and built fabrics. Environmental activism is traditionally understood as a reaction, chiefly by groups of people, against a perceived external threat.

In the 60's and 70's, an activist stance began to emerge in the work of some artists and architects, who used creative methods such as performances, happenings, temporary spatial interventions etc to convey their political/aesthetic messages.' Some of this work engaged directly with communities but predominantly it was the production of one individual working 'outside' society. However such actions demonstrated not only the power of the visual in conveying a political message but also the potential of conceptual creative approaches to reveal alternative values and hidden potentials. This marked a shift from activism as protestation towards an activism of reconceptualisation.

Recently, activist groupsii have developed a more politically informed process. Whilst their 'tools' may resemble work from the 60's and 70'siii, their methodologies are nontraditional, 'rhizomatic', pedagogical and fluid; working alongside, rather than against, the established power and funding structures. Such creative processes build new, often unexpected, stakeholder networks; offer neutral spaces in which contentious issues can be faced; and create better understanding of values and identities. They can also lead to permanent improvements and development in the physical fabric.

This paper will discuss a pedagogical example of activism in architectural education. The event (www.fourdaysontheoutside.com) is in its fifth year of existence and as such has revealed a value and impulse beyond its learning and teaching value.

The paper will discuss how the event contributes to the university's outreach programme and how its structure acts as a seedbed for potential research projects and partnerships. UK Universities talk extensively about applied research but have few actual strategies by which to generate it. Fourdaysontheoutside offers some potential ways forward.

\section{Context}

UK Higher Education is currently experiencing a range of unprecedented challenges: increasing student numbers (39\% overall increase between 1995 and 2003), decreasing resources, pressure on staff/ student contact time (due to quality assurance of teaching and research). In addition, Architectural Education is faced with an increasingly bureaucratic professional double-validation system (ARB and RIBA) that requires evidence of output, to meet the criteria for validation. Increasingly, input must be justified and mapped directly against output. In other words we are almost at the point where we can only teach that which can be assessed.

Such a position reduces the potential for experimentation, critical enquiry, risk-taking etc, all of which are at the heart of creative courses; and all are activities that we, in architectural education, associate specifically with the design studio.

This situation will have a potentially catastrophic impact on the quality, experience and 'space' of learning in architecture. There is clearly a need to resist this trend but there is also a danger in standing still whilst we resist.

From within our own discipline, there are persistent calls for change in architectural education, specifically the design studio, (Dutton, Koch, Schwennsen et al, Till, Morrow etc). To face these challenges we must begin to think of ways to consolidate teaching/learning, research, and outreach activities.

This paper looks at one small educational event: 'fourdaysontheoutside', currently in existence in 2 schools of architecture in the UK that may provide some clues to ways forward.

The paper will provide a brief description of the event and some examples of the projects that have made up the event over the last 5 years. It will analyze the project within the context of 'live'/'real' projects and an agenda of Activism, highlighting the range of benefits offered by such an event; and finally draw some conclusions on issues that require further development.

\section{An alternative?: fourdays...}

fourdaysontheoutside represents a modest attempt to demonstrate the existing value and hidden potentials of 
architectural processes by stepping temporarily outside the academy. From its inception, it has aimed to make the activities and skills of students and staff visible to as wide a range of communities and stakeholders as possible. fourdays... concisely encapsulates the ethos of the new architecture course in Belfast, that is: to be an active, visible and contributing partner in the built environment. It offers an opportunity to reveal the context and mechanisms of change and the possible collective, personal and professional contributions to the processes of change. Parallel to this agenda of civic involvement is an understanding of the pedagogical benefits of such activities. fourdays.. can be understood as part of a stimulating, if sporadic, legacy of activist pedagogies.

fourdaysontheoutside is a pedagogical event which places the architecture course for four days on the outside of the academy. It has run for the last 5 years in the first year of the undergraduate architecture course both at the University of Sheffield, England and since two years at the University of Ulster, Belfast, Northern Ireland.

As an 'event' it has 2 core aims:

- To bring the public's attention to the architecture course as a local creative resource and

- To fully exploit the pedagogical benefits of 'live' projects.

The event is made up of concurrent projects. Each project involves students working in small groups (10-12) with external practitioners drawn from a wide range of backgrounds (architecture, art, music, theatre etc..) and in separate locations. Some groups are student led.v Each group project has the same limited timescale (4 days) and limited budget (£100).

The event brief asks only that both process and product of the week are carried out with, or in ways visible to, people beyond the school. It does not require nor indeed anticipate an outcome. Sometimes this translates into working with community groups, individual clients or simply in public space. The method of working is group based and although the outcomes relate to the built environment, they are not necessarily architectural. Some projects resemble exhibitions, protests, happenings, consultative processes etc., whilst other groups build constructions in the public realm. The external practitioners set the agenda, much as a

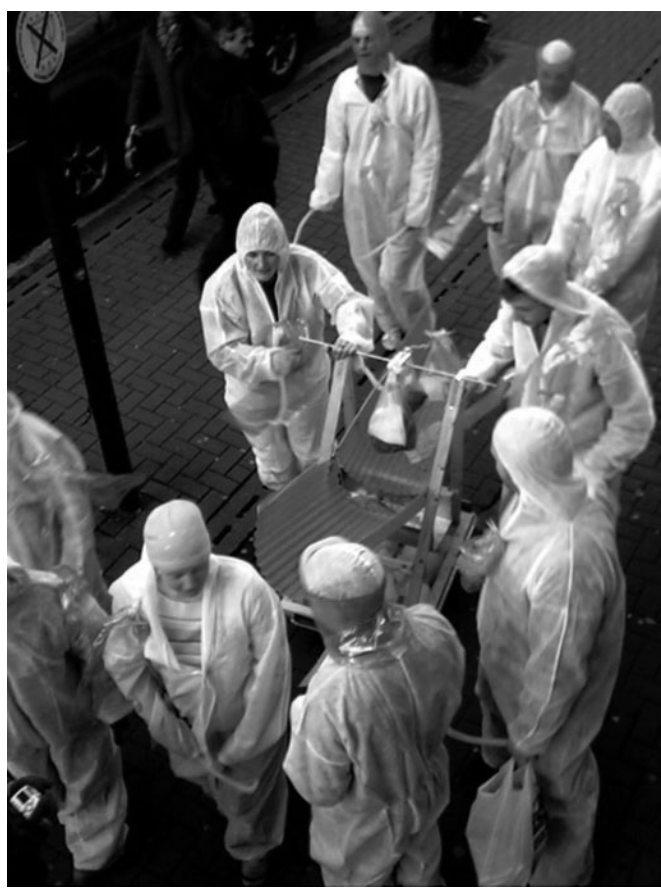

figure 1: The water carriers 2004: students devised city centre demonstration to show relationship between society, water and environment.

client would, and the students establish a timetable and goals for the 4 days.

At the end of the fourdays, a 'fifth day' offers the opportunity to publicly present the products and processes of the event and reflect on the relevance of the activities to the students' learning and their future roles within the built environment. This fifth day is fundamental to the event's success; the act of making 'sense' of the projects within the event is where 'deep learning' occurs. In the last 2 years, this final discussion of the event projects has also moved out of the design studio and into official cultural venues, open to the public (Ormeau Baths Gallery 2005, Belfast Exposed Gallery 2004). This is an attempt to engage yet other 'publics' in the internal 'teachings' of the academy.

From the start fourdays... has used the internet to increase its visibility and to encourage students to understand the value of documenting their work. In each fourdays.. event, one small group of student documents the process of the 


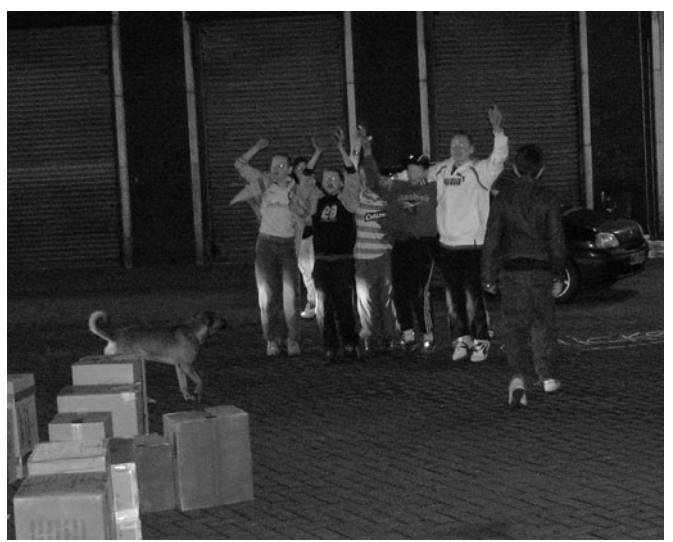

figure 2: the audience for architectural 'crit'

event from their own perspective and builds or feeds a website. In Feb 05, external funding allowed us to employ designers to create a permanent home for the event: the webcity exists at www.fourdaysontheoutside.com.

As webcity develops it will be used to 'brand' the event and promote it to future partners

\section{The importance of partnering}

fourdays.. is a time-consuming and resource-heavy activity (practitioner/student ratios of 1:10 or 1:12 are costly) and it has become increasingly important to identify ways to spread its resourcing amongst several partners and in return share its potential. This reflects a context where those involved in the management of architecture courses in the UK are gradually realising the need to identify sources of funding beyond that of the higher education funding councils, if they are to sustain a worthwhile and vibrant architectural culture.

fourdays.. has gradually focused on developing both internal and external partnerships. Forming external partnerships increases the scope and life span of the event. At one level it brings external voices into a collective dialogue about the urban realm but importantly, it also brings resources in the form of in-kind contributions (advice, locations, contacts, etc) and actual funding of practitioners, materials, etc.

Initially the event was financed through visiting lecturer funds and drew on informal, in-kind support. However, over the last two years the event has attracted internal university funding from the Cultural Development Support Scheme in the University of Ulster. This scheme, supporting arts and cultural events organised by staff, aims to "establish a 'bridgehead' between the university and the wider world contributing to the growth and expression of the cultural richness of the University for the benefit of staff, students and the region as a whole". The Cultural Development team also helps to promote and, more significantly, identify other external sources of funding. In the last two years the event has noticeably increased its partnerships, with 7 of the 10 projects in 2005 partnered in some aspect of their work e.g. a local arts festival and a national retail developer funded two groups of external practitioners. Equally, the generosity of local architects, planners and public bodies, in terms of time and information, adds considerably to the event.

Interestingly, partnerships seem also to legitimize the process for the students, confirming that at some level, their experiences during fourdays.. are both serious and meaningful.

\section{Examples of projects within fourdays...}

Each event (staged every February) has between 5 and 10 projects. The following section describes a selection of the projects, including a short reflection of the key learning experiences. (other projects can be viewed on the website)

\section{occupying space Feb 05}

practitioner: local architect / urban designer

location: Derry/ Londonderry

partners: Derry City Centre Initiative

supported by: $\quad$ Derry's Urban Design Regeneration

Company and local Planning Service reps.

Late Thursday evening after days of standing in the cold, counting teenagers, mapping movement, noting social status, consulting owners, sketching, and photoshopping, eight students prepare to present their analysis and design proposals on the actual site of their investigation (a public space known as "the fountain"). The students lay out toytown models in a chalked up city plan on the patched pavers and project their design visions onto a sheet hung between lamp post and tree in the centre of one of Derry's most contested spaces. Late night shopping offers the hope of a few interested passers-by and the buzz of fluorescent light. 
Gradually, the square attracts its full set of players. Drugged-up youths commandeer the left over chalk to write political slogans in rings around the 'architectural crit'; passing drunks proffer hymns and prose; a street angel (courtesy of the City Centre Initiative) attempts to corral a group of boys intent on stealing the projector; whilst a squad car circles sporadically, keeping all under observation on a typical Thursday evening.

Whether out of bewilderment or composure, the students remain calm, allowing each 'interaction' to play itself out. What should have been a 20-minute presentation was finally completed in 2 hours.

Amongst many things, this project made the contrast between abstract design visions and the realities of such public spaces real and acute.

\section{connecting places Feb 05}

practitioners: 2 architects / 1 urban planner location: Shankill, Lower Falls and Carlisle Circus, North Belfast partners: PLACE (Belfast's centre of the built environment) and Westfield Developers

The three practitioners are all local activists and advocates for a better quality, more sustainable, socially equitable urban environment. Working with students they head off in search of barriers and solutions to barriers in the fractured, nonsensical, troubled urban landscape that lies to the northwest of Belfast's 'consume centre.'

After walking and mapping and narrowly avoiding becoming a road accident statistic, the students begin to realise the

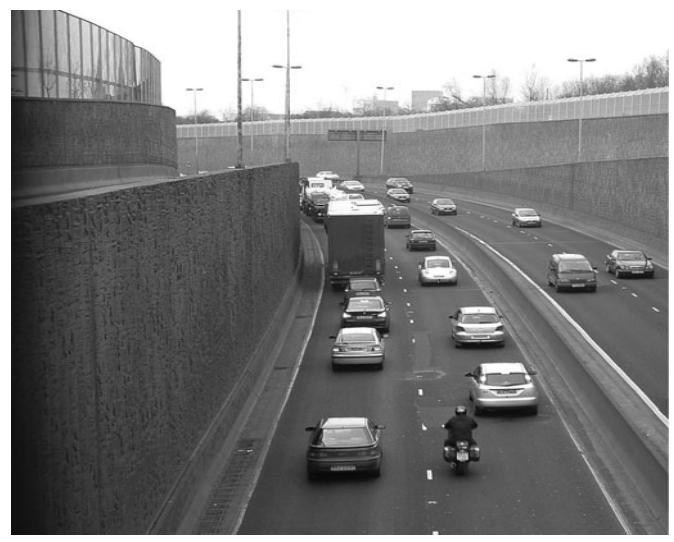

figure 3 : the 'trench' between north / west Belfast and City centre. nerve and fleetness of foot required by the local population when walking into the city centre.

The barriers are numerous; both physical and psychological:

The defensive moat of the Westlink, a dual carriage, which was gouged out during the troubles.

The high street 'highway', with seemingly no destination and astonishingly few pedestrian crossings.

And finally, the city centre cordon of vacant lots and monolithic blank facades- the accepted expression of service yards and security conscious development.

The students presented their finding formally to an audience of civil servants and developers in the Centre of the Built Environment. One trend of particular interest was revealed by the students' study: the use of new build old people's homes as buffers in areas of interface; placing each community's elders on a desert island in a sea of traffic.

\section{studio ReLimitE Feb 05}

practitioner: Citymine(d) and architect (London)

location: Botanic Gardens, South Belfast

partners: British Council (indirectly)

City Mine(d) is a Brussels/London/Barcelona based production house for urban interventions that reappropriates public space to make it the arena for social, cultural and artistic encounter. In the months prior to fourdays.. City Mine(d) had deconstructed one of their

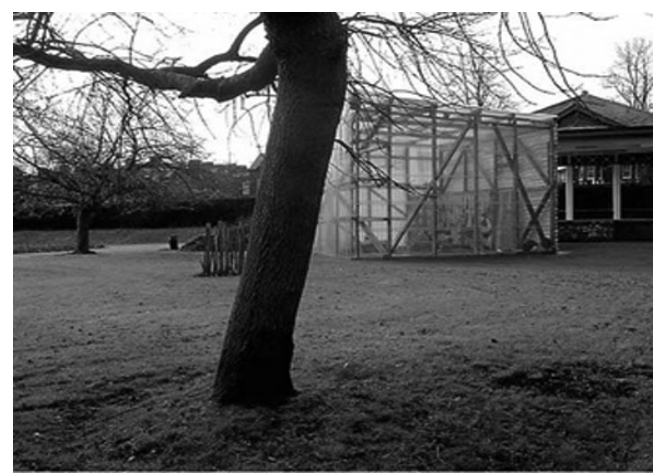

figure 4: re-erected City Mine(d) tower 
projects in Brussels and with funding from the British Council and the help of trainee builders in Brussels and Belfast, transported and re-erected the tower (on its side) in the Botanic Gardens. The students were asked to inhabit the tower for the duration of the 4 days, whilst investigating the manifestation of 3 networks of employment 1 unemployment; green (organic) and live music scene; with the purpose of proposing possible future uses for the temporary construction.

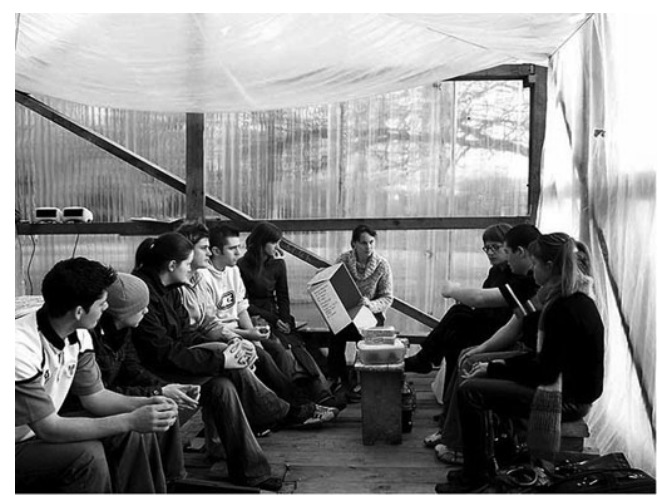

figure 5 : students inhabiting the structure

The students discovered the creative potential of programming one space with a variety of unrelated and at times, conflicting uses. Those involved also exhibited strong survival skills and an overt ability in entrepreneurial activity, effectively demonstrating how to transform a space into a place with the minimum of resources.

\section{the window dressers Feb 04 \\ practitioners: $\quad 1$ local architect \\ Location: Linenhall Street/Belfast \\ Partners: $\quad$ Property owner, Ulster Architectural Heritage Society}

A local architect wanted to demonstrate to a client the value of one of his vacant properties. He asked the students to prove its worth to the owner. They consulted historians, libraries, conservationists and planners, converted the empty ground floor shop unit into an ad hoc exhibition space and presented their investigations and outcomes, illustrating to the owner, and anyone walking by, the historical/ social/ economic and architectural potential of the building.
The students learnt to locate historical information and local area plans. They learnt that in order to convey such information effectively, they had to imbue it with value and present with creativity. They discovered that part of an architect's role is to educate and inspire.

\section{exchanging places Feb 03}

Practitioners:

2 Sheffield Diploma students

Location: Wharncliffe Works, Green Lane, Sheffield

Partners: Owner and Developer and surrounding businesses

This project was organised by diploma students and based on the idea of exchange as a system for obtaining objects, labour or services through swapping and credit. The owner and developer allowed them to use a courtyard site in exchange for clearing the site of waste materials at the end of the project. They collected the materials that had accumulated in the site over the years and categorised them into metal and glass, stone, and wood. One group was assigned to each category and a central shop was set up offering miscellaneous items. Each group then had to build an installation from the materials it had and any it could barter through the central shop, where not only objects, but also tools, and labour could be exchanged.

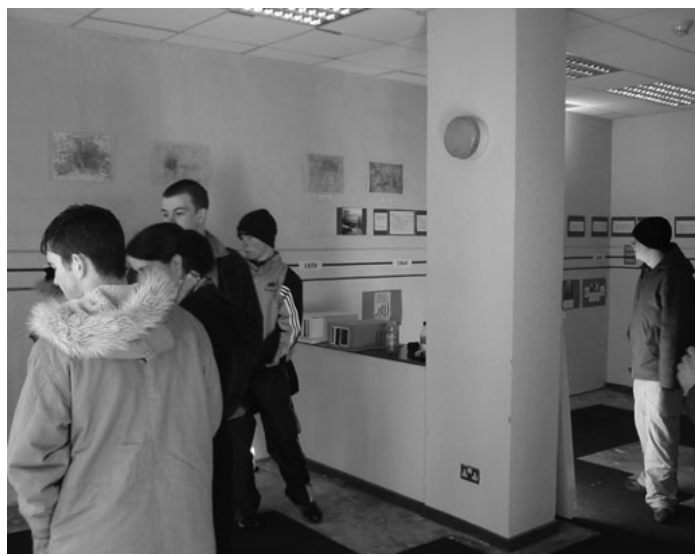

figure 6: ad-hoc exhibition in converted shop space.

The students established that the value of materials relies on the marketplace. Within their exchange system, timber became more expensive that glass, stone or metal since it was easy to transport and easy to utilise. They also learnt 
that sometimes design skills are secondary to the skills of bartering and negotiation and that creativity can depend more on what's on offer than what's imaginable.

\section{Unpicking fourdays... Pedagogical Context}

As an event fourdays.. belongs to a genre identified in the UK as the 'Live Project'. Rachel Sara defines a live project as "a type of design project that is distinct to traditional studio projects in their engagement of real clients or users, in real-time settings." One of the best known forms of the live project is the internationally acclaimed Rural studio, whose mission is...

"..to enable each participating student to cross the threshold of misconceived opinions to create/design/build and to allow students to put their educational values to work as citizens of a community. The Rural Studio seeks solutions to the needs of the community within the community's own context, not from outside it. "

Live projects have the recognised strengths of :

- Drawing close to the actual experience of architectural practice

- Exposing students to views of people beyond the studio and the profession.

- Allowing students to develop a 'sustained and sustainable creativity' at ease in the context of tight briefs, budgets and timescales.

- Promoting collaborative rather than individual practices.

Being a highly motivational and effective way to learn (experiential learning)

However live projects also contain clouded and unresolved issues. Their raison d'être remains the 'built-thing' - ie buildings, extensions, insertions, installations, small scale or temporary structures, or at very least a design proposal for a built-thing. Whilst there is an acknowledgement of the value of the process, the natural default of most architects and architectural educators is to give preference to the delivery of a product. However, this has implications on the logistics of live projects within an educational framework (Chiles p98). Certainly, within undergraduate level in the UK, the university modular structure and the demands of professional validation leave little space for live projects in "real-time settings". By their nature, live projects involve teamwork and although external bodies actively support this, universities still struggle when managing the summative assessment of group work at degree level. Assessment of such holistic (and hence complex) projects presents methodological challenges.

Live projects also bring with them some ethical concerns. There is a responsibility when engaging with clients and users beyond the studio. Pedagogical aims can, in the course of the project, be compromised by or indeed compromise the nature of the project. Relationships that aren't built on hard-cash need trust and trust takes time to build. Therefore it is important to discuss expectations and desired outcomes throughout the process, particularly where the client I user group is vulnerable to disappointment. Live projects naturally bring concerns (and opportunities!) about health and safety and but they also raise the uneasy question of whether such projects sits within the territory of architectural practice and whether students / staff collaborations are taking work from their professional colleagues. Of course there are some live projects that work in territories in which few architectural practices could sustain themselves, eg. Rural Studio and Thomas Dutton's Centre for Community Engagement, who work with communities who can't afford 'architecture'.

As architectural education persists in polarising abstraction and reality, those who seek to bring 'real-world' experiences into the design studio, view built projects are the only 'real' way to teach students. Architectural education remains guilty of insufficiently intellectualising what it is teaching and, more importantly, how. No matter what, we still seem to mark 'the building'!

four days.. looks to other models; models of practice that architects themselves have and do engage in (fluid models of activism, community engagement alongside art practices) for ways to teach students the skills that produce those products that we so badly desire.

\section{Breaking through.}

The event fourdays.. overcomes some of the dilemmas of live projects by

1. being un-assessed (un-graded) from its inception. Assessment of all of the learning outcomes of such a complex project would have involved a disproportionate amount of effort in relationship to the scale of the project. Focusing on only one aspect of the project to assess, for example: evidence of entrepreneurship, creativity, material 
skills, team-working, etc would have put more weight onto one aspect of the project altering its holistic learning profile. But it was also felt that in order to guarantee high levels of creativity and risk-taking that the project should be free of summative assessment though not formative.

2. being only $4+1$ days long, it is easier to resource and fits straightforwardly into an academic programme. However its brevity belies its impact and challenges conventional university learning that stretches over one or two semesters. Short, experience-based projects match modes of learning all too infrequently addressed in the context of university learning. The experience and memory of fourdays... stays with the students long after the conclusion of their undergraduate studies.

3. not necessarily resulting in a 'built -thing'. Although some of the projects end in a construction (or design for a construction) there is no expectation of this at the start; the products and processes evolve out of the context. However the fifth day is where we discuss the significance of all the projects and particularly the non-built projects. Students are asked to identify skills applied and developed in the week that they think are relevant to the role of an architects. This opens up much wider critical discussions around the architect's role and place in society.

4. building partnerships. fourdays.. has realised that in order to become sustainable it has to work at developing long term relationships of trust and creativity. Such partnership may lead to funding but of equal importance is the fact that our partners carry fourdays.. and its activities beyond the university into other constituencies and locations. Students and University benefit from these extended networks in ways difficult to measure.

In summary four days.. allows students to:

- Learn about the pace, levels of production and bravery needed to bring short projects to successful completion. Understand that a context of tight budgets and limited timescale demands a heightened sense of creativity, relying on compromise, improvisation, humour, risk taking.

- Begin to develop the ability to negotiate the use/ occupation of/access to space with various stakeholders.

- Develop team working and collaborative skills.

- Understand the importance of effective documentation /communication.
- Develop ability to look afresh and critically at everyday situations, and reconceptualise them. (this is particularly challenging within the context of a troubled city like Belfast). - Develop manual skills.

- Start to understand the necessity of intellectualising their actions in order to connect localised activity/experience to the wider context of learning.

\section{Research Potential}

fourdays.. reflects the interests and ambitions of the new Centre of Research in Art, Technologies and Design. Interface; in particular, the research area of art in contested spaces in the research strand 'Art and its Locations'.

"Interface is interested in the way fourdays... is often situated at the public interface of urban sites in Northern Ireland, which are inhabited and used by members from different communities. It views the event as intervening in the everyday rituals and the spacio-temporal structures that underwrite and conventionalise them in order to break open habitual patterns of perception, thought and behaviour/ action. fourdays.. also reveals and brings attention to contemporary practices and the interface of architecture, design, urban planning, activism and performance."

The Research Centre contributed to the documentation of the event in 2005, and intends in the coming year to map the event against the interests of the research centre by sharing visiting lecturer resources to support the funding of external practitioners. There is potential for Interface to pursue in more depth some of the issues that emerge from the various projects, identifying alternative ways to practice. Fourdays.. offers the possibility of revealing future areas of applied research with ready-made partners and potential sponsors, consolidating in one 'event' the activities of teaching/ learning, research and outreach.

\section{Conclusion: where next?}

fourdays.. evolves each year, and with each year its potential becomes clearer. On the surface it is a very recognisable model and an easy concept to grasp. This is part of its success. Its profile as an 'event' means that it has gradually developed from teaching tool to an annual cultural event in the landscape of Belfast. Its scale accommodates risk and allows for a relaxed attitude towards failure as much as success. But, it does take enormous individual effort and conviction to organise. 
In anticipation of next year, the aim is therefore to develop co-ownerships with other partners both within and outside the university. Internal collaborations have been attempted in the past but strangely collaborative, action-based creative practice is not as common as one would imagine; even amongst artists.

The website will develop as a resource which captures not only fourdays.. but other initiatives with similar concerns. A Handbook is currently being developed which will speak directly to students, practitioners, partners and other participants. The experience of fourdays.. means that whilst we can't predict outcomes we have begun to recognise patterns, and identify areas that can be considered in advance. The Handbook will also explain the context of fourdays.. and outline its scope in order that all involved are aware of its limitations and possibilities. An evaluation section will be included. To date fourdays.. has been informally evaluated by partners, funders, students and external examiners - though in many ways its clearest marker of success is its vividness.

In terms of intellectual context, fourdays.. will become better informed by ongoing research into forms of activism that use collaborative creative processes as a shared pedagogical experience, one where not only students learn about the value and potential of the built environment, but also, those who witness and work with them.

\section{Endnotes:}

'See work of Coop Himmelblau, Archigram, Vito Acconci, Utopie, the Situationists, Beuys' social sculptures etc "Groups such citymine(d) (Brussels), urban catalyst (Berlin), platforma 198 (Zagreb), aaa (paris), GlasCooP (Glasgow) CBAT (cardiff) etc

iii For example: Citymine(d)'s ball and bubble (2000/ 2002) resembles Coop Himmelblau's bubble (1968?) and Archigram's 'cushicle' (1968)

\section{References:}

Angus, Michael. "Trigger Paper: Process and Product within the Studio: 'Real/ Not Real' ." Studio Culture 2: Touching the Real. A Conference for Teachers in Schools of Architecture and Landscape. Edinburgh, 15th - 16th Dec 2004.

Biden, Noak K, Ameet Hiremath, Hannah Purdy, editors (2003) Perspecta 34: Temporary Architecture. The Yale Architectural Journal, MIT Press.
"A Brief Introduction to UK Higher Education: Notes for NMS Mentors from outside the HE Sector for the Leadership Foundation for Higher Education." The Council for Industry and Higher Education. 19th February $2006<$ www.ciheuk.com/docs/MentoringOverviewofsector0505.pdf>.

Buchanan, Peter. "What is Wrong with Architectural Education? almost Everything." The Architectural Review 185.1109 (1989): 24-6.

Chiles, Prue. "The 'Real' Client and the 'Unreal' Project." Changing Architectural Education: Towards a New Professionalism. Ed. David Nicol and Simon Pilling. London: E \&FN Spon, 2000. 91-99.

Dessauce, Marc (ed) (1999) The inflatable Moment: pneumatics and protest in '68. Princeton Architectural Press, New York.

Dutton, Thomas A., and Lian Hurst Mann. Reconstructing Architecture : Critical Discourses and Social Practices. Vol. 5. Minneapolis: University of Minnesota Press, 1996.

Dutton, Thomas A. Voices in Architectural Education Cultural Politics and Pedagogy. New York: Bergin \& Garvey, 1991.

Hurst Mann, Lian. "Subverting the Avant-Guarde: Critical Theory 's Real Strategy ." Reconstructing Architecture: Critical Discourses and Social Practices. Ed. T. Dutton and L. Hurst Mann. vol 58166 ed. Minneapolis: University of Minnesota Press, 1991. 259-318.

John, Richard. Crinson, Mark and Lubbock, Jules. Architecture: Art Or Profession? Three Hundred Years of Architectural Education in Britain. (Manchester: Manchester University Press/Prince of Wales Institute of Architecture). 1995.

Koch, A., et al. The Redesign of Studio Culture. Washington: The American Institute of Architecture Students., 2002. Miles, Malcolm. Urban Avant-Gardes : Art, Architecture and Change. London: Routledge, 2004.

Morrow, Ruth, Judy Torrington, and Rosie Parnell. "Reality Versus Creativity." Transactions: online journal of centre for education in the built environment 1.2 (2006): 19th February 2006. <www.cebe.heacademy.ac.uk/transactions/index.php $>$

Nicol, David, and Simon Pilling, eds. Changing Architectural Education. London: E \&FN Spon, 2000. 